Of further interest is the form of the psychoses; the present cases combined with those reported previously have been restricted to 11 paranoid and four manic illnesses. Functional psychoses are, by tradition, broadly divided into schizophrenic and affective groups. Among patients with schizophrenia, however, a subgroup has been postulated with "positive" symptoms associated with acute illness and a good response to dopamine blocking neuroleptics. ${ }^{13}$ Similar drugs are also known to be effective in mania, ${ }^{14}$ and bromocriptine has been reported to exacerbate manic symptoms. ${ }^{15}$ Dopamine receptors may possibly take part in the pathogenesis of both paranoid and manic illnesses despite the traditional diagnostic distinction, and this common pathogenetic mechanism may be the cause of a superficial likeness in aspects of their clinical symptomatology. Although in our group all the women developed paranoid illnesses and the two men became manic, a much larger series would be required to establish any significant sex difference.

Although the reactions reported above were almost certainly due to the dopamine agonists per se, it must be noted that little is known of the incidence of psychotic symptoms in untreated acromegaly or hyperprolactinaemia. Apart from isolated case reports,,$^{16-18}$ only generalised anecdotal comment is available. In our series neither endocrine state nor the pattern of response to treatment was predictive of a psychiatric relapse. We believe, in view of the time course of relapse and remission and the relation to drug treatment, that these illnesses were not simply a reflection of the underlying endocrine disorder.

Clearly, these side effects must be recognised in view of the particular strain that may be placed on the patients and their families. Alterations in day to day behaviour, non-compliance with treatment, unusual changes in work or social life, unaccountable moodiness or misery are all suggestive and should alert the physician. The stigma of such illness remains strong, and we cannot absolutely exclude the possibility that some cases have gone unrecognised. Nevertheless, it must be emphasised that only eight out of 600 patients treated with dopamine agonists definitely developed this type of reaction.

These studies were supported by the Joint Research Board of St Bartholomew's Hospital and the Peel Medical Research Trust.

\section{References}

Serby M, Angrist B, Lieberman A. Mental disturbance during bromocriptine and lergotrile treatment of Parkinson's disease. Am f Psychiatry 1978;135:127-9. Long-term treatment of parkinsonism with bromocriptine. Lancet 1978; i:735-8. psychosis in

Proctor AW, Littlewood R, Fry AH. Bromocriptine-induced psychosis in acromegaly. $\mathrm{Br}$ Med $1983 ; 28$.

Mental disorders from low-dose bromocriptine. $N$ Engl f Med

6 Steinbeck K, Turtle JR. Treatment of acromegaly with bromocriptine. Aust NZ f Med 1979;9:217-24

7 Vlissides DN, Gill D, Castelow J. Bromocriptine-induced mania? Br Med $1978 ; \mathrm{i}: 510$.

8 Brook NM, Cookson IB. Bromocriptine-induced mania ? Br Med $\mathcal{F}$ 1978; ; :790 9 Cookson JC. Post-partum mania, dopamine and oestrogens. Lancet 1982;ii:672. 0 Gerner RH, Post RM, Bunney WE. A dopaminergic mechanism in mania. Am f Psychiatry 1976;133:1177-80.

1 Parkes D Bromocriptine. N Engl f Med 1979;301:873-8.

12 Reilly TM, Jopling WH, Beard AW. Successful treatment with pimozide of

13 Crow TJ. Positive and negative schizophrenic symptoms and the role of dopamine. Br f Psychiatry 1980;137:383-6.

14 Silverstone T, Cookson I. The biology of mania. In: Granville-Grossman K, ed. Recent advances in clinical psychiatry. Vol 4. London: Churchill Livingstone,
1982:204-41.

15 Johnson JM. Treated mania exacerbated by bromocriptine. Am $f$ Psychiatry 1981;138:980-2. 16 Pye IF, Abbott R. Bromocriptine-induced psychosis in acromegaly. $\mathrm{Br} \mathrm{Med} \mathcal{F}$
1983;286:50-1.

17 Margo A. Acromegaly and depression. Br f Psychiatry 1981;139:467-8

8 Davison K, Bagley CR. Schizophrenia-like psychoses associated with organic isorders of the central nervous system: a review of the literature. In: Herrington RN, ed. Current problems in neuropsychiatry. Ashford, Kent: Headley Brothers, 1969:126-30. (Br F Psychiatry special publication No 4.) 19 Munro A. Monosymptomatic hypochondriachal psychosis. $\mathrm{Br} f \mathrm{Hosp}$ Med

(Accepted 8 August 1984)

\begin{abstract}
A series of 103 early postmenopausal women completed a questionnaire about their dietary calcium intake and were then divided into three groups: those with an intake below $550 \mathrm{mg} /$ day, those with an intake between 550 and $1150 \mathrm{mg} / \mathrm{day}$, and those with an intake above $1150 \mathrm{mg} / \mathrm{day}$. Thereafter they were given a daily supplement of $500 \mathrm{mg}$ calcium for two years and had their bone mineral content measured every three months. Any changes found were taken as an estimate of bone calcium balance.

All three groups showed a similar fall in bone mineral content over the two years, indicating that a calcium intake of $1000-2000 \mathrm{~g}$ daily is ineffective in preventing bone loss in the early menopause.

\footnotetext{
Department of Clinical Chemistry, Glostrup Hospital, University of Copenagen, Denmark

L NILAS, MD, physician

C CHRISTIANSEN, MD, director
}

Department of Clinical Physiology, Aalborg Hospital, Denmark P RØDBRO, MD, director

Correspondence to: Dr L Nilas, Department of Clinical Chemistry, Glostrup Hospital, DK-2600 Glostrup, Denmark.
\end{abstract}

\section{Introduction}

The amount of bone lost yearly in the period immediately after the menopause approaches $2 \%$. Although this rate then declines, bone loss will reach such a magnitude that by the age of 70 some $40 \%$ of women will have had at least one spontaneous postmenopausal fracture. ${ }^{1}$ Hip fracture, the most severe, is associated with a six month mortality of $20 \%$, and the incidence of these fractures seems to be increasing. ${ }^{2}$ Since there is no treatment for osteoporosis, some means of prevention is urgently required. Oestrogen may delay or prevent postmenopausal bone loss $^{3-5}$ and reduce the risk of fractures. ${ }^{6}$ This effect is probably dose related, ${ }^{7}$ and there is evidence that a combination of calcium and oestrogen may increase bone mass. ${ }^{3}$ Calcium balance is almost invariably negative in early postmenopausal women. Oestrogen probably impedes bone resorption, resulting in a decreased loss of calcium. Although it might be possible to identify potential fast bone mass losers, such women may not readily accept hormone treatment, and we cannot exclude the risk of unwanted side effects of long term administration.

The search for an agent that will increase bone mass has been intensive. Dihydroxycholecalciferol $\left(1,25(\mathrm{OH})_{2} \mathrm{D}\right)$ stimulates calcium absorption, but its effect on bone mass, and that of its analogue $1 \alpha-\mathrm{OHD}$, has proved disappointing. ${ }^{3}{ }^{8}$ Heaney et al found a positive correlation between calcium intake and 
calcium balance in both premenopausal and postmenopausal women ${ }^{10}$; they claimed that daily calcium intakes of 1000 and $1500 \mathrm{mg}$ respectively would achieve calcium balance and that larger intakes would result in positive calcium balance. Since more than $99 \%$ of the body's calcium is deposited in bones, a positive calcium balance must lead to increased bone calcium. This would imply that calcium is the agent of choice for preventing osteoporosis; also calcium is cheap, simple to administer, and does not have serious side effects. A long term preventive study with calcium, however, calls for a valid estimate of long term calcium balance.

Bone mineral content measured on the forearm correlates well with total bone calcium, ${ }^{11}$ so that measurement at intervals should permit an estimate of calcium balance. Over two years we measured bone mineral content as a function of time in early postmenopausal women with differing calcium intakes in order to see if calcium intake influenced calcium balance.

\section{Subjects and methods}

We studied 103 early postmenopausal women who received a daily supplement of $500 \mathrm{mg}$ calcium (Sandoz) for two years. All had had a normal menopause six months to three years before and none had a history of diseases or of receiving drugs known to influence calcium metabolism. Details of the selection procedure are given elsewhere. ${ }^{3}$

At the beginning of the trial the participants filled in a questionnaire about their average daily intake of dairy products (milk, cheese, etc), and this was used to estimate their average calcium intake. Apart from dairy products, calcium mostly comes from drinking water; all the participants resided in the same area with a high calcium content in the tap water, and an additional intake of $300 \mathrm{mg}$ daily was presumed. This figure was calculated as the difference between the known mean daily dietary intake of calcium in the Danish population at large and the mean intake of the study group from dairy products alone.

The participants were stratified into the following three groups according to their calculated calcium intake. Group 1 comprised 29 women with a daily calcium intake below $550 \mathrm{mg}$ (mean $430 \mathrm{mg}$, median $470 \mathrm{mg}$ ); group 2 comprised 55 women with a daily calcium intake of 550 to $1150 \mathrm{mg}$ (mean $880 \mathrm{mg}$, median $860 \mathrm{mg}$ ); and group 3 comprised 19 women with a daily calcium intake above $1150 \mathrm{mg}$ (mean $1640 \mathrm{mg}$, median $1250 \mathrm{mg}$ ) (see table I). Overall the 103 women had a mean daily calculated total calcium intake of $910 \mathrm{mg}$ (median $850 \mathrm{mg}$; range $390-2350 \mathrm{mg}$ ), with a normal distribution skewed to the right. Tables I and II give the relevant clinical data and initial calcium metabolic variables.

TABLE I-Relevant clinical data on 103 postmenopausal women stratified according to daily dietary calcium intake. Values are means (1 SD in parentheses)

\begin{tabular}{lcrr}
\hline & $\begin{array}{c}\text { Low } \\
\text { (group 1; } \\
\mathrm{n}=29)\end{array}$ & $\begin{array}{c}\text { Medium } \\
\text { (group 2; } \\
\mathrm{n}=55)\end{array}$ & $\begin{array}{c}\text { High } \\
\text { (group 3; } \\
\mathrm{n}=19)\end{array}$ \\
\hline Postmenopausal age (months) & $18 \cdot 6(11 \cdot 1)$ & $22 \cdot 7(10 \cdot 8)$ & $15 \cdot 6(9 \cdot 2)$ \\
Weight (kg) & $65 \cdot 2(10 \cdot 3)$ & $64 \cdot 9(11 \cdot 2)$ & $63 \cdot 2(12 \cdot 1)$ \\
Height (cm) & $162 \cdot 3(5 \cdot 1)$ & $162 \cdot 0(5 \cdot 7)$ & $161.5(6 \cdot 7)$ \\
Serum creatinine ( $\mu$ mol/1) & $80(10 \cdot 0)$ & $70(10 \cdot 0)$ & $70(10 \cdot 0)$ \\
Urinary creatinine excretion (mmol/24 h) & $9 \cdot 8(1 \cdot 6)$ & $10 \cdot 1(1 \cdot 9)$ & $10 \cdot 0(2 \cdot 4)$
\end{tabular}

Conversion: SI to traditional units-Serum creatinine: $1 \mu \mathrm{mol} / 1 \approx 0.01 \mathrm{mg} / 100 \mathrm{ml}$ Conversion:
Urinary creatinine: $1 \mathrm{mmol} / 124 \mathrm{~h} \approx 0.1 \mathrm{~g} / 24 \mathrm{~h}$.

TABLE II-Initial calcium metabolic variables in 103 postmenopausal women stratified according to daily dietary calcium intake. Values are means (1 SD in parentheses)

\begin{tabular}{|c|c|c|c|}
\hline & $\underset{\substack{\text { Low } \\
n=29)}}{\text { (group } 1}$ & $\begin{array}{c}\text { Medium } \\
\text { (group 2; } \\
\mathrm{n}=55 \text { ) }\end{array}$ & $\underset{\text { (group } 3 ;}{\text { High }}=19$; \\
\hline $\begin{array}{l}\text { Urinary calcium excretion rate (mmol/ } \\
\text { mmol creatinine) } \\
\text { Serum calcium (mmol/1) } \\
\text { Serum phosphate (mmol/l) } \\
\text { Serum alkaline phosphatase (U/1) } \\
\text { Serum parathyroid hormone (ng/l) } \\
\text { Bone mineral content (arbitrary units) }\end{array}$ & $\begin{array}{c}0.58(0.26) \\
2.46(0.08) \\
1.1(0.1) \\
146(29) \\
25(13) \\
37.2(6.6)\end{array}$ & $\begin{array}{c}0.61(0.26) \\
2.44(0.07) \\
1.1(0.1) \\
159(49) \\
30(22) \\
38.1 \quad(6.5)\end{array}$ & $\begin{array}{c}0.66(0.25) \\
2.46(0.07) \\
1.1(0.2) \\
159(62) \\
29(11) \\
39.1(7.0)\end{array}$ \\
\hline
\end{tabular}

Conversion: SI to traditional units-Serum calcium: $1 \mathrm{mmol} / 1 \approx 4 \mu \mathrm{g} / 100 \mathrm{ml}$. Conversion: $S I$ to traditional units-
Phosphate: $1 \mathrm{mmol} / 1 \approx 3.1 \mathrm{mg} / 100 \mathrm{ml}$.
Bone mineral content was measured by photon absorptiometry (iodine-125) and calculated as the mean of 12 scans (six on each forearm) on the distal part of the forearms; results were expressed in arbitrary units $(\mathrm{g} / \mathrm{cm})$. This method has a long term reproducibility of $1-2 \%$ in normal subjects. ${ }^{12}$ Bone mineral content and urine and blood biochemical values were determined at the start of the study and every three months for two years.

Alkaline phosphatase activity and concentrations of inorganic phosphate, creatinine, and protein were determined by standard procedures in our laboratory. Calcium was measured by atomic absorptiometry, and the serum concentration was corrected to a serum protein value of $70 \mathrm{~g} / \mathrm{l}$. Serum parathyroid hormone was determined by a mainly $\mathrm{N}$ terminal specific radioimmunoassay..$^{13}$ The excretion of calcium was calculated as mmol calcium per mmol creatinine in $\mathbf{4 8}$ hour urine collections.

Calculations and statistical evaluation-For each participant the initial values of all variables were taken as $100 \%$ and all subsequent measurements expressed as a percentage of that value. The rate of bone change for each subject was calculated by linear regression and expressed as the percentage change per year. The significance of changes within groups (difference between initial and final values) was determined by paired Student's $t$ test. Changes in bone mass among groups were compared by analysis of variance.

\section{Results}

Figure 1 shows the individual differences between initial and final values for bone mineral content in the three groups. The three mean values did not differ significantly, and the standard deviations were closely similar. The changes in mean serum concentrations of calcium,

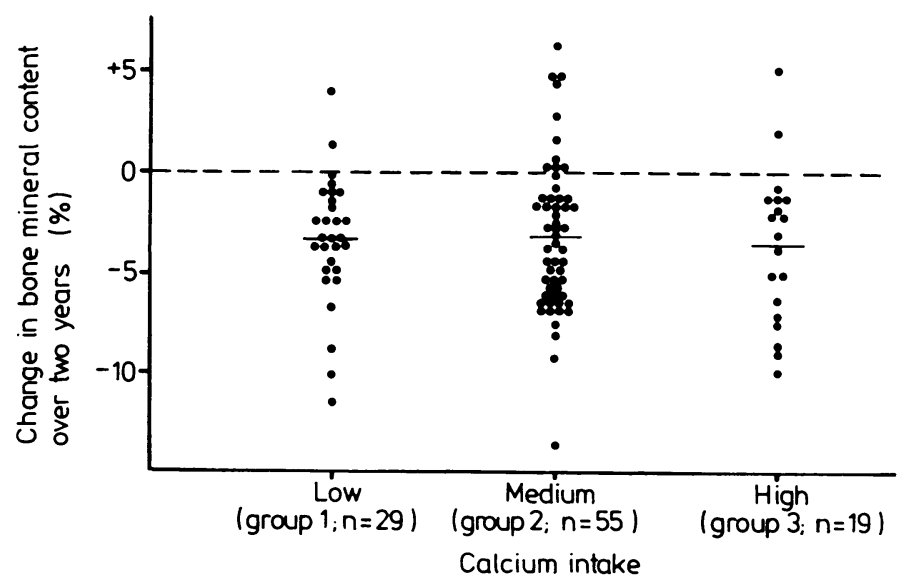

FIG 1-Individual changes in bone mineral content during two years of calcium supplementation in 103 normal postmenopausal women subdivided according to daily calcium intake. Bars are means.

phosphate, and parathyroid hormone were small, insignificant, and did not differ among the groups. Figure 2 gives the mean percentage changes in bone mineral content and urinary calcium excretion as a function of time. In the three groups the slopes of the regression of bone mineral content on time were $-0.43,-0.40$, and -0.50 , and none was significantly different from the overall slope of $-0 \cdot 42$. The corresponding $\mathrm{r}$ values were $-0.92,-0.99$, and -0.99 , respectively, compared with an overall value of -0.99 .

There was continuous bone loss in all three groups, the yearly loss reaching $1.9 \%, 1.6 \%$, and $2.0 \%$ respectively during the two years $(\mathrm{p}<0.001)$. In all three groups calcium excretion rose within three months of starting the daily supplement of $500 \mathrm{mg}$ calcium $(\mathrm{p}<0 \cdot 05-0.01)$. The percentage rise was greatest in group 1, with the lowest calcium intake. After the first three to six months calcium excretion fell $(p<0.01-0.001)$ in all groups, reaching the initial value in groups 2 and 3 after 18 months to two years, but remaining above that value in group 1 . When the participants were stratified (into three groups) according to initial calcium excretion rate no differences were seen in the rate of bone loss; nor, when stratified according to the rate of bone loss, were there any differences in the initial or final calcium excretion values, and the estimated dietary calcium intakes were similar in the three groups. 


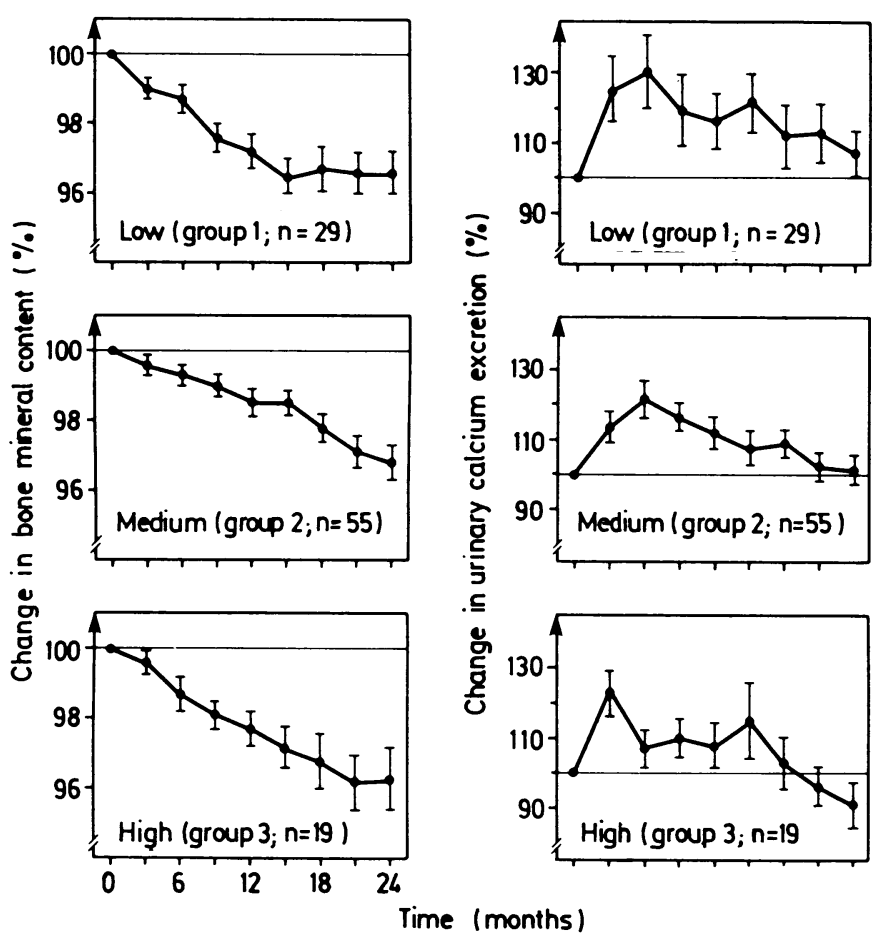

FIG 2-Mean changes in bone mineral content and urinary calcium excretion in 103 normal postmenopausal women subdivided according to daily calcium intake. Values expressed as percentage of initial. Bars are 1 SEM.

\section{Discussion}

The 103 women in this study were a representative sample of all Danish women in early menopause, ${ }^{3}$ and the three groups were well matched (tables I and II). We did not measure actual dietary calcium intake; nevertheless, that the estimate obtained by questioning did, to some extent at least, reflect differences in calcium intake is supported by the differences in calcium excretion.

When the participants were stratified according to bone loss no differences in calcium intake or excretion were found; this suggests that other factors determine the rate of bone loss. "Fast losers" may have been inadvertently overrepresented in the high calcium intake group, whereby a possible beneficial effect of calcium would have been masked. This does not seem to have been the case, however, since menopausal age, body weight, alkaline phosphatase activity, and hydroxyproline excretion were identical in the three groups and an increase of these values, among others, characterises fast losers. ${ }^{14}$ Moreover, the distribution of fast and slow losers within the three groups did not differ significantly (fig 1 ). In the statistical evaluation of bone loss with age we calculated the individual slopes, the slopes of the mean values (fig 2 ), and the differences between the initial and final values of bone mineral content (fig 1). All three types of calculation gave virtually the same results, indicating that the decreases in bone mass during the two years of observation were relatively linear. In all the calculations we took the initial value as $100 \%$ and expressed the subsequent measurements as a percentage of that value. Each measurement of bone mineral content was calculated as the mean of 12 scans, which partly accounts for the high precision and makes several baseline measurements unnecessary.

Heaney et al reported that calcium balance and intake are related, and that in postmenopausal women a calcium intake above $1400 \mathrm{mg}$ daily will lead to a positive calcium balance. ${ }^{10}$ According to their results the balance should have been negative in our group 1, almost zero in group 2, and positive in group 3. Heaney $e t a^{15}$ and others ${ }^{16} 17$ also claimed that calcium supplementation leads to increased bone mass. Irrespective of calcium intake identical and significant reductions in bone mass were seen in all three groups in our study (fig 2). Only 14 of the 103 women actually showed a positive difference (fig 1). When the 14 women with the highest calculated calcium intakes (above $1800 \mathrm{mg} /$ day including the $500 \mathrm{mg}$ supplement) were compared with the 14 with the lowest calculated calcium intakes, no difference was found in the mean change in bone mineral content $(-3.9 \% v-4.1 \%$ over two years). Similarly, the 14 women with positive changes in bone mineral content and the 14 with the most negative showed similar initial calcium intakes (1390 mg $v 1520 \mathrm{mg}$ including the $500 \mathrm{mg}$ supplement). Interestingly, the person with the highest calculated calcium intake ( $2350 \mathrm{mg}$ daily) had a loss of bone mineral content of $4.5 \%$ a year no matter how stratification was done. Calcium intake is higher in Denmark than in the United States, and we cannot exclude the possibility that a calcium supplement would benefit women with a calcium depleted diet. On the other hand, our subjects in group 3 (high calcium intake) were definitely losing calcium from their bones (fig 2). Thus even if the calculated calcium intakes in our study are considered to be inaccurate there is still no evidence of a relation between bone loss and calcium intake.

The question arises whether it is possible to have reduced bone mineral content values without being in negative calcium balance. More than $99 \%$ of the body's calcium is located in bones. Our method measured only $1.2 \%$ of the total bone mass. At the measuring site, however, the relation between cortical and trabecular bone is similar to the distribution in the whole body. ${ }^{1819}$ Measurements of bone mineral content can be done with high accuracy $(3 \%)$ and precision $(1.4 \%)$. The local value is closely related to total bone mineral mass in both normal subjects and patients with various diseases of calcium metabolism. ${ }^{11}$ It therefore seems most unlikely that the women had a positive calcium balance, including those in group 3 (high calcium intake).

With a skeletal calcium content of about $900 \mathrm{~g}$ the calculated yearly rate of bone loss of $1 \cdot 6-2 \cdot 0 \%$ corresponds to a daily calcium loss of $50 \mathrm{mg}$. The following factors tend to validate our findings: high precision of measurement, a reasonably large number of representative subjects, and a long observation period (more than 700 days), during which the small daily loss accumulates to a degree which can be measured reliably and accurately. With regard to conventional balance studies it must be remembered that although calcium intake under optimal conditions can be measured with high precision, the same does not necessarily hold true for calcium output, and one tries to measure a difference between two magnitudes of almost equal size. Furthermore, for an increasing intake the difference will tend to be a decreasing percentage. Systemic errors in determining calcium output (in conventional balance studies) will lead to a more positive calcium balance during increasing calcium intake. In other words, since our findings for bone mineral content contradict the results from calcium balance studies ${ }^{910}$ the conclusion seems inescapable that the methodologically superior "integral" way of estimating early loss (from long term bone mineral content studies) will yield more valid results than the "differential" method of calcium balance studies with its potential systematic errors.

The results indicate that a calcium intake of $1000-2000 \mathrm{~g}$ daily has little effect on loss of bone calcium in the early menopause.

\section{References}

1 Jensen GF, Christiansen C, Boesen J, Hegedüs V, Transbøl I. Epidemiology of postmenopausal spinal and long bone fractures. Clin Orthop 1982;166:75-81. 2 Jensen JS. Trochanteric fractures. Acta Orthop Scand 1981;52 (suppl 188):1-27. 3 Christiansen C, Christensen MS, McNair P, Hagen C, Stocklund K-E, Transbøl I. Prevention of early postmenopausal bone loss: controlled 2-year study in 315 normal females. Eur $\mathcal{F}$ Clin Invest 1980;10:273-9.

4 Nachtigall LE, Nachtigall RH, Nachtigall RD, Beckman EM. Estrogen replacement therapy I: a 10-year prospective study in the relationship to osteoporosis. 5 Marshall DH, Horsman A, Nordin BEC. The prevention and management of 
post-menopausal osteoporosis. Acta Obstet Gynecol Scand 1977;65 (suppl): $49-56$

6 Weiss NS, Ure CL, Ballard JH, Williams AR, Daling JR. Decreased risk of fractures of the hip and lower forearm with postmenopausal use of estrogen

7 Christensen MS, Hagen C, Christiansen C, Transbøl I. Dose-response evaluation of cyclic estrogen/gestagen in postmenopausal women. Placebo-controlled trial of its gynecologic and metabolic actions. Am f Obstet Gynecol 1982;144: 873-9.

8 Christiansen C, Christensen MS, Rødbro P, Hagen C, Transbøl I. Effect of 1,25-dihydroxy-vitamin $D_{3}$ in itself or combined with hormone treatment in preventing postmenopausal osteoporosis. Eur $\mathcal{F}$ Clin Invest 1981;11:305-9.

9 Heaney RP, Recker RR, Saville PD. Calcium balance and calcium requirements in middle-aged women. Am $\mathcal{f}$ Clin Nutr 1977;30:1603-11

10 Heaney RP, Recker RR, Saville PD. Menopausal changes in calcium balance performance. F Lab Clin Med 1978;92:953-63.

11 Gotfredsen A, Als O, Tjellesen L, Nilas L, Borg J, Christiansen C. Clinical applicability of in vivo estimation of total body bone mineral by dual photon absorptiometry. Measurements on normals and osteopenic patients. $\mathcal{f}$ Comput Assist Tomogr 1983;7:558-9.

12 Christiansen C, Radbro P. Long-term reproducibility of bone mineral content

13 Christensen MS. A sensitive radioimmunoassay of parathyroid hormone in human serum using a specific extraction procedure. Scand $\mathcal{f}$ Clin Lab Invest $1976 ; 36: 313-22$

14 Christiansen C. Osteoporosis and vitamin D metabolites. A status report. In Norman AW, Schaefer K, Herrath DU, Grigoleit H-G, eds. Vitamin D. Chemical, biochemical and clinical endocrinology of calcium metabolism. Berlin, New York: Walter de Gruyter, 1982 :915-20.

Effect of estrogens and calcium carbonate on bone loss in postmenopausal women. Ann Intern Med 1977;87:649-55. on bone loss in postmenopausal women. Ann Intern Med 1977;87:649-55.
Horsman A, Gallagher JC, Simpson M, Nordin BEC. Prospective trial of
oestrogen and calcium in postmenopausal women. Br Med $\mathcal{F} 1977 ;$ ii :789-92. Riggs BL, Seeman E, Hodgson SF, Taves DR, O'Fallon WM. Effect of fluoride/calcium regimen on vertebral fracture occurrence in postmenopausal osteoporosis. N Engl $\mathcal{F}$ Med $1982 ; 306: 446-50$.

18 Melsen F, Nielsen HE, Christensen P, Mosekilde Li, Mosekilde Le. Some relations between photon-absorptiometric and histomorphometric measurements of bone mass in the forearm. In: Mazess RB, ed. Proceedings of fourth international conference on bone measurement. Bethesda, Md: National Institutes of Health, 1980:45-50. (NIH publication No 80-1938.

19 Snyder WS, Cook MJ, Nasset ES, Karhausen LR, Howells GP, Tipton IH. Report on the task group on reference man. ICRP 23. Oxford: Pergamon Press,

(Accepted 14 August 1984)

\title{
Detection of arrhythmia: limited usefulness of patient activated recording devices
}

\author{
L E THOMAS, L M SHAPIRO, E J PERRINS, K M FOX
}

\begin{abstract}
The findings of 24 hour ambulatory electrocardiography and monitoring with the Cardiomemo, a device recording 32 seconds of electrocardiogram during symptoms, were compared in 20 patients with symptoms suggestive of arrhythmia. Ambulatory electrocardiography showed arrhythmia in seven patients, extrasystoles in six, and normal findings in seven. Nine patients failed to transmit any Cardiomemo recordings, and the Cardiomemo failed to show ventricular and supraventricular tachycardia. It did not show any appreciable arrhythmia in the seven patients with normal 24 hour electrocardiograms.

The Cardiomemo does not offer any important advantages over ambulatory electrocardiography, and its relative cheapness is outweighed by the limited number of patients who can use the device in one year. It can, however, reassure anxious patients of the absence of arrhythmia during symptoms.
\end{abstract}

\section{Introduction}

Patients who present with syncope, palpitations, and dizziness are often difficult to diagnose at first presentation, many requiring further investigation to determine the cause of their symptoms. Continuous 24 hour ambulatory electrocardiography has an established place in the investigation of these patients, ${ }^{1}$ but, particularly in patients with relatively infrequent symptoms, a single 24 hour recording may not give sufficient information. In addition, the probability of recording an actual attack is small. Devices are currently being evaluated that allow patients to record a 32 second strip of electrocardiogram when symptoms occur. ${ }^{2}{ }^{3}$ The electrocardiogram is stored in a solid state memory

National Heart Hospital, London W1M 8BA

L E THOMAS, MB, MRCP, registrar

L M SHAPIRO, MD, MRCP, senior registrar

E J PERRINS, BSC, MRCP, senior registrar

K M FOX, MD, MRCP, consultant cardiologist

Correspondence to: Dr K Fox. and may be replayed at a convenient time via a transtelephonic link to the local investigation centre. We compared the information recorded by one of these new devices, Cardiomemo, with the results of standard 24 hour ambulatory electrocardiography in 20 unselected patients.

\section{Patients and methods}

We studied 20 consecutive patients who presented with dizziness, syncope, or palpitation and in whom the resting electrocardiogram did not show any arrhythmia. They were aged 13 to 71 ; two complained of dizziness, three of syncope and dizziness, and 15 of palpitation. A detailed description of the presenting symptom was recorded using a standardised questionnaire that included questions about the frequency and duration of the symptom of the supposed arrhythmia and the presence of pre-existing heart disease. A resting 12 lead electrocardiogram was recorded using Hewlett-Packard equipment.

The Cardiomemo (Instromedics) is a small $(6 \times 3 \times 1$ inch) device for recording the electrocardiogram during symptoms. The four integral electrodes are placed either on the chest or on fingers of both hands. An event button activates 32 seconds of solid state digital memory. The stored electrocardiogram is later transmitted by telephone to the hospital and decoded by a Cardiotel receiver (Instromedics). Each patient was given a Cardiomemo to be used whenever symptoms developed.

Ambulatory electrocardiography-Single channel 24 hour ambulatory electrocardiography was performed in all patients. The electrocardiograms were analysed by an experienced technician using a Reynolds Pathfinder Replay II system and related to each patient's symptoms during the period of study. All arrhythmias were interpreted by one of us.

\section{Results}

Of the 20 patients given a Cardiomemo, 11 successfully transmitted a symptomatic episode and nine made no transmission. Those who transmitted sent one to six recordings (median three). Ambulatory electrocardiography identified appreciable arrhythmia in seven patients, only three of whom transmitted Cardiomemo recordings. In the four others the Cardiomemo failed to show both ventricular and supraventricular tachycardia (table). Of six patients with extrasystoles according to ambulatory electrocardiography, three transmitted Cardiomemo recordings showing similar findings, one did not transmit, and two transmitted only sinus rhythm, suggesting that the extrasystoles may not have been the cause of the symptoms. Of 